Research Article

\title{
Molecular cloning and characterization of a novel freezing-inducible DREB1/CBF transcription factor gene in boreal plant Iceland poppy (Papaver nudicaule)
}

\author{
Zhuo Huang ${ }^{1}$, Jiao $\mathrm{He}^{1}$, Xiao-Juan Zhong ${ }^{1}$, Han-Du Guo ${ }^{1}$, Si-Han Jin ${ }^{1}, \mathrm{Xi} \mathrm{Li}^{1}$ and Ling-Xia Sun ${ }^{1}$ \\ ${ }^{1}$ College of Landscape Architecture, Sichuan Agricultural University, Wenjiang, Sichuan, China.
}

\begin{abstract}
DREB1 of the AP2/ERF superfamily plays a key role in the regulation of plant response to low temperatures. In this study, a novel DREB1/CBF transcription factor, PnDREB1, was isolated from Iceland poppy (Papaver nudicaule), a plant adaptive to low temperature environments. It is homologous to the known DREB1s of Arabidopsis and other plant species. It also shares similar 3D structure, and conserved and functionally important motifs with DREB1s of Arabidopsis. The phylogenetic analysis indicated that the AP2 domain of PnDREB1 is similar to those of Glycine max, Medicago truncatula, and $M$. sativa. PnDREB1 is constitutively expressed in diverse tissues and is increased in roots. qPCR analyses indicated that PnDREB1 is significantly induced by freezing treatment as well as by abscissic acid. The expression levels induced by freezing treatment were higher in the variety with higher degree of freezing tolerance. These results suggested that PnDREB1 is a novel and functional DREB1 transcription factor involved in freezing response and possibly in other abiotic stresses. Furthermore, the freezing-induction could be suppressed by exogenous gibberellins acid, indicating that PnDREB1 might play some role in the GA signaling transduction pathway. This study provides a basis for better understanding the roles of DREB1 in adaption of Iceland poppy to low temperatures.
\end{abstract}

Keywords: DREB1, expression profile, freezing stress, Iceland poppy, transcription factor.

Received: September 2, 2015; Accepted: March 29, 2016.

\section{Introduction}

Abiotic stress conditions, such as drought, high salinity, and cold, have adverse effects on plant growth and production. As sessile organisms, plants have developed a wide spectrum of adaptation strategies to cope with the inevitable challenges of environmental stress. Many aspects of these adaptation processes, including developmental, physiological and biochemical changes, are regulated by stress-responsive gene expression. Transcription factors (TFs) play pivotal roles in gene expression by regulating expression of downstream genes as trans-acting elements via specifically binding to $c i s$-acting elements in the promoters of target genes. The cis- and trans-acting elements involved in the transcriptional responses of stress-responsive genes have been previously identified (YamaguchiShinozaki and Shinozaki, 2006).

The APETALA 2/ethylene-responsive element binding factor (AP2/ERF) superfamily is a large group of TF, usually classified to the AP2, RAV, and ERF families (Sakuma et al., 2002; Licausi et al., 2013). The ERF family

Send correspondence to Zhuo Huang. College of Landscape Architecture, Sichuan Agricultural University, 211 Huimin Road, 611130 Wenjiang, Sichuan, China. E-mail: duoduo609@sina.com is further subdivided into ERF and DREB (dehydration-responsive element-binding protein) subfamilies based on different conserved amino acid residues within their respective AP2 domains (Nakano et al., 2006; Lata and Prasad, 2011; Lata et al., 2011). Among these, many members of DREB subfamily are involved in plant abiotic stress responses by regulating gene expression via the cisacting dehydration-responsive element/C-repeat (DRE/CRT, A/GCCGAC) element (Yamaguchi-Shinozaki et al., 2006, Kidokoro et al., 2015) in the promoters of stress responsive genes, such as COR15A, RD29A/COR78, and COR6.6 (Stockinger et al., 1997; Liu et al., 1998; Sakuma et al., 2002; Licausi et al., 2013).

The DREB1 subgroup of DREB subfamily are major regulators of cold-stress responses. Three out of the six DREB1s of Arabidopsis, DREB1A/CBF3, DREB1B/CBF1 and $D R E B 1 C / C B F 2$ are rapidly induced in response to cold stress (Stockinger et al., 1997; Liu et al., 1998; Gilmour et al., 1998; Shinwari et al., 1998). The overexpression of $A t D R E B 1 / C B F$ led to up-regulated expression of coldinducible genes that function in survival at low temperatures, including those encoding late embryogenesis abundant (LEA) proteins and enzymes for sugar metabolism and fatty acid desaturation (Maruyama et al., 2004; Seki et al., 
2001; Fowler and Thomashow 2002). Additionally, the expression levels of $D R E B 1 B / C B F 1$ and $D R E B 1 C / C B F 2$ are significantly correlated with freezing tolerance (Hannah et al., 2006). Heterologous expression of DREB1 was capable to improve multiple abiotic stress tolerances in agricultural crops including tobacco (Kasuga et al., 2004), wheat (Pellegrineschi et al., 2004), rice (Ito et al., 2006), chrysanthemum (Hong et al., 2006a,b,c; Hong and Kim, 2005), and Caragana korshinskii (Wang et al., 2011), etc.

Cold-inducible DREB1/CBF genes have been isolated from numerous dicotyledonous plant species, such as oilseed rape, Vaccinium myrtillus (Oakenfull et al., 2013), Caragana korshinskii (Wang et al., 2011), Capsicum annuum (Hong and Kim, 2005), grape (Xiao et al., 2006), and chrysanthemum (Tong et al., 2009), as well as monocotylous plant species, such as wheat (Triticum aestivum), rye (Secale cereale) (Jaglo et al., 2001), rice (Dubouzet et al., 2003), maize (Qin et al., 2004), etc.

Iceland poppy (Papaver nudicaule) is a dicotyledonous and boreal flowering plant, native to subpolar regions of Europe, Asia and North America, and the mountains of Central Asia. It is adapted to low temperature environments and has been widely utilized as ornamental plants because it yields large, papery, bowl-shaped, lightly fragrant flowers supported by hairy, one foot, curved stems among feathery blue-green foliage 1-6 inches long. Previous studies mainly focused on extraction and analyses of its alkaloid (Philipov et al., 2007; Istatkova et al., 2008; Tatsis et al., 2014). However, no attention has been paid on their acclimation to low temperatures. Our previous study investigated the physiological responses and tolerance of four varieties of Iceland poppy to low temperatures (from 3 to $-9{ }^{\circ} \mathrm{C}$ ) (unpublished). To further understand it's low temperature adaptation at molecular level and reveal novel cold responsive genes, we cloned and characterized a new $D R E B 1$ gene member, named PnDREB1, from the Iceland poppy variety Champagne Bubbles, which has prominent freezing tolerance among four varieties previously investigated (unpublished). Sequence similarity and phylogenetic relationship to the known DREB1s were comprehensively analyzed, and its spatial expression patterns and responses to freezing stress and phytohormone were also investigated.

\section{Materials and Methods}

\section{Plant materials and treatments}

A variety of Iceland poppy, Champagne Bubbles (CB), was used for gene cloning and expression analyses. Another variety, Wonderland (WL), with lower freezing performance was also used in expression analysis. Seeds were surface-sterilized with hydrogen peroxide solutions and germinated on plates containing the mixture of local soil and nutrient soil (with a ratio of 1:1). The seedlings were maintained in a greenhouse with a relative humidity of $50-70 \%, 12 \mathrm{~h}$ light at $15^{\circ} \mathrm{C}$ and $12 \mathrm{~h}$ dark at $10^{\circ} \mathrm{C}$. After three or four leaves emerged, the plants were transferred to plastic pots with $15 \mathrm{~cm}$ diameter (one plant per pot).

For freezing treatment, the four-month-old plants with uniform growing status were carefully pulled out from the soil. After cleaning the roots with distilled water, the plants were cultured into Hoagland's solution for three days under normal condition and then transferred into an incubator at $0{ }^{\circ} \mathrm{C}$ with light. The leaf and root tissues were sampled at $0,2,4,8,12,24 \mathrm{~h}$ post treatment; For ABA treatment, the plants were treated in 100 Hoagland's solution containing $100 \mu \mathrm{M}$ ABA (Shan et al., 2007) under normal growth condition and the leaf and root tissues were sampled at $0,0.5,1,2,4,8$ and $12 \mathrm{~h}$; For gibberellin (GA) treatment, the $80 \mu \mathrm{M} \mathrm{GA}_{3}$ solution containing $0.02 \%(\mathrm{v} / \mathrm{v})$ polyoxyethylene-sorbitan monolayrate (Tween-20) were evenly sprayed onto the whole plant. Two hours later, the plants were transferred to freezing treatment and leaf tissues were sampled at $0,0.5,1,2,4,8$ and $12 \mathrm{~h}$ (Shan et al., 2007). Each treatment was repeated three times. Samples consisted of equal tissue quantities from 3 individual plants, which were immediately frozen in liquid nitrogen and stored at $-80{ }^{\circ} \mathrm{C}$ until their use.

\section{Nucleic acid extraction}

Genomic DNA was isolated from leaves of seedlings with the cetytrimethylammonium bromide (CTAB) procedure as reported by Murray and Thompson (1980). Total RNA in various tissues was extracted according to the manual of the TRIZOL Kit (TIANGEN, Beijing). The qualities and quantities of extracted nucleotide were measured by NanoDrop 2000 (Thermo Fisher, USA).

\section{Amplification of conserved region of DREB1}

About $5 \mu \mathrm{g}$ of total RNA was reverse transcribed with oligo18(dT) primer by using single-stranded cDNA Synthesis Kit (TaKaRa Dalian, China) following the manufacturer's introduction. To amplify the conserved region of $D R E B 1$ from Iceland poppy, a pair of degenerate primers, DREB1-F1 and DREB-F2, was designed based on the alignment of nucleotide sequences of AP2 domains of DREB1s of Arabidopsis, Glycine max, Nicotiana tabacum, Vitis vinifera, Chrysanthemum, and Prunus mume (Table $1)$.

The Polymerase Chain Reaction (PCR) amplifications were performed in $25 \mu \mathrm{L}$ reaction volume, consisting of $1 \mathrm{U}$ Ex-Taq DNA polymerase (TaKaRa), $2.5 \mu \mathrm{L}$ PCR buffer (supplied with Taq DNA polymerase), $1 \mu \mathrm{L}$ cDNA template, 400 pmol of each primer, $1.5 \mathrm{mM} \mathrm{MgCl}_{2}$ and 200 $\mu \mathrm{mol}$ of each dNTP. PCR program was conducted as following: $94{ }^{\circ} \mathrm{C}$ for $5 \mathrm{~min}, 30$ cycles at $94{ }^{\circ} \mathrm{C}$ for $20 \mathrm{~s}, 56{ }^{\circ} \mathrm{C}$ 
Table 1 - Primer sequences for expression level evaluation.

\begin{tabular}{|c|c|c|c|c|}
\hline Primer Name & Sequence $\left(5^{\prime}-3^{\prime}\right)$ & Target gene & Expected size (bp) & Usage \\
\hline DREB1-F2 & CGAACAGTTCTCAACAGTTATCATC & PnDREB1 & 400 & Semi quantity RT-PCR \\
\hline DREB1-R2 & CTCACTATATTGATAAGTTGGACTC & & & \\
\hline actin-F2 & TTGGATTCTGGTGATGGTGT & Actin1 & 300 & Semi quantity RT-PCR \\
\hline actin-R2 & GAACCTCTGGACAACGGAACC & & & \\
\hline actin-F4 & ATGCCCTACCACATGCCATC & Actin1 & 86 & QPCR \\
\hline actin-R4 & ACCACGCTCCGTCAAGATTT & & & \\
\hline ef1-F2 & GGAGGCTGCTGAGATGAACA & $E F 1$ & 77 & QPCR \\
\hline ef1-R2 & CACGCTCACGTTCAGCCTTA & & & \\
\hline DREB-F3 & GCTACACCAGAAATGGCTGC & PnDREB1 & 95 & QPCR \\
\hline DREB-R3 & CTCCAGACGGAATCAGCGAA & & & \\
\hline
\end{tabular}

for $20 \mathrm{~s}, 72{ }^{\circ} \mathrm{C}$ for $20 \mathrm{~s}$, followed by $72{ }^{\circ} \mathrm{C}$ for $10 \mathrm{~min}$ and incubation at $12{ }^{\circ} \mathrm{C}$. Amplified fragments were separated on $1 \%$ agarose gels, and purified using agarose gel DNA purified Kit (TIANGEN, Beijing). Purified fragments were ligated onto pEASY-T1 vector (Transgene Beijing). Five positive clones were screened by PCR with M13 universal primers and sequenced on ABI 3730 sequencer (Invitrogen, Shanghai).

\section{Amplification of 3' and 5' ends of DREB1}

The Rapid Amplification of cDNA Ends (RACE) technology was employed to obtain 3' and 5' ends of the target gene. To amplify the 3' end of DREB 1 from Iceland poppy, the gene-specific primers 3'RACE-GSP1 and 3'RACE-GSP2 were designed based on the sequence of conserved region of DREB1 obtained in a previous step (Table 1). Using the cDNA as template, PCR amplifications were performed using primer pair 3'RACE-GSP1 and 3UPM. The composition of the PCR mixture was the same as described above. The PCR was conducted as following program: $94{ }^{\circ} \mathrm{C}$ for $5 \mathrm{~min}, 30$ cycles at $94^{\circ} \mathrm{C}$ for $30 \mathrm{~s}, 54^{\circ} \mathrm{C}$ for $40 \mathrm{~s}, 72^{\circ} \mathrm{C}$ for $1 \mathrm{~min}$, followed by $72{ }^{\circ} \mathrm{C}$ for $10 \mathrm{~min}$ and incubation at $12{ }^{\circ} \mathrm{C}$. The resulting solution was 20 -fold diluted and $1 \mu \mathrm{L}$ was used as template in the second round of PCR by primer pair 3'RACE-GSP2 and 3UPM. The reaction mixture and program were the same as the first round of PCR. The final amplified products were also cloned and sequenced as previously described.

The 5' end of DREB1 was obtained by using 5' Full RACE Kit (Takara, Dalian). All reaction mixtures and programs were performed according to the protocols provided by the manufacture. The annealing temperatures for the first and second rounds of PCR amplifications were $55^{\circ} \mathrm{C}$ and $53{ }^{\circ} \mathrm{C}$, respectively. The subsequent PCR product separations, purifications, cloning, and sequencing were done as described above. The primers used are listed in Table 1.

\section{Obtaining full sequences of DREB1 of the Iceland poppy}

The two primers, DREB1-F2 and DREB1-R2, were designed based on the full length cDNA of DREB1 and were subjected to amplification of full cDNA and genomic sequences of DREB1. PCR amplifications were performed in $50 \mu \mathrm{L}$ reaction volume, consisting of $2 \mathrm{U}$ Taq HiFi DNA polymerase (TRANSGENE, Beijing) with high fidelity, 5 $\mu \mathrm{L}$ of HiFi buffer (supplied with DNA polymerase), $2 \mu \mathrm{L}$ cDNA or DNA templates, 200 pmol of dNTP mixture, and 400 pmol of each primer. The PCR program was: $94^{\circ} \mathrm{C}$ for 5 min, 10 cycles at $94{ }^{\circ} \mathrm{C}$ for $30 \mathrm{~s}, 49^{\circ} \mathrm{C}$ for $30 \mathrm{~s}, 72^{\circ} \mathrm{C}$ for 1 min, 34 cycles at $94{ }^{\circ} \mathrm{C}$ for $30 \mathrm{~s}, 55^{\circ} \mathrm{C}$ for $30 \mathrm{~s}, 72{ }^{\circ} \mathrm{C}$ for $1 \mathrm{~min}$, and a final extension at $72{ }^{\circ} \mathrm{C}$ for $10 \mathrm{~min}$. The resulting products were also gel-separated, purified, cloned, and sequenced.

\section{Bioinformatics analyses}

The deduced protein sequence was predicted by BioEdit (Hall, 1999). The homology modeling of DREB1 protein was performed by SWISS-MODEL with automated mode (Biasini et al., 2014). The model with the highest sequence similarity to the template and highest GMQE and QMEAN4 scores was chosen to predict the three-dimensional structure. Sequence similarity to the known DREB1s was investigated by BLASTP search against the nr protein database available on the website of National Center of Biotechnology Information and The Arabidopsis Information Resource (TAIR, http://www.arabidopsis.org).

The motifs in each protein were analyzed by Multiple Em for Motif Elicitation (MEME version 4. 10.1) (Timothy and Charles, 1994). The AP2/ERF domain in each DREB1 was identified by SMART (Letunic et al., 2012) and the corresponding sequence was retrieved. Multiple sequence alignment of amino acids of the AP2/ERF domain was conducted by using MUSCLE (Edgar, 2004) with default options. Motif logo representing the consensus sequence of AP2/ERF domains was drawn by using WebLogo (Crooks 
et al., 2004). MEGA5.2 software was employed to reconstruct the phylogenetic tree by maximum likelihood method, with 1000 bootstrap replications (Tamura et al., 2011). The Jones-Taylor-Thornton (JTT) model and a discrete Gamma distribution $(+\mathrm{G})$ with 5 rate categories were chosen based on the test model.

\section{Semi quantitative reverse transcription PCR (RT-PCR)}

The spatial expression of $P n D R E B 1$ in petal, pedicel, leaf, petiole, and root were evaluated by semi quantitative RT-PCR. The primers used are listed in Table 1 and Actin 1 was set as internal standard gene. As the sequence of Actin1 was unknown in Iceland poppy, we amplified and sequenced the Actin 1 using primers (actin-F1 and actin-R1) (Table S1) designed from known sequences of a wide range of plant species (data not shown) (Figure S1). Then, a pair of primers (actin-F2 and actin-R2) was designed for semi quantitative RT-PCR analysis (Table 1). The $1 \mu \mathrm{L}$ of $10 \mathrm{di}-$ luted cDNA reaction mixture was used as template in a 25 $\mu \mathrm{L}$ PCR volume. The PCR programs were: $94{ }^{\circ} \mathrm{C}$ for $3 \mathrm{~min}$ followed by 6 cycles of $94{ }^{\circ} \mathrm{C}$ for $30 \mathrm{~s}, 55^{\circ} \mathrm{C}$ for $30 \mathrm{~s}, 72{ }^{\circ} \mathrm{C}$ for $30 \mathrm{~s}$, and 19 (for actin 1) or 24 (for PnDREB1) cycles of $94{ }^{\circ} \mathrm{C}$ for $30 \mathrm{~s}, 60{ }^{\circ} \mathrm{C}$ for $30 \mathrm{~s}, 72{ }^{\circ} \mathrm{C}$ for $30 \mathrm{~s}$, and a final 72 ${ }^{\circ} \mathrm{C}$ for $5 \mathrm{~min}$. The amplifications for two genes were performed simultaneously in the same PCR thermal cycler with three replicates. The amplified products were separated by $1 \%$ agarose gel electrophoresis and visualized by ethidium bromide staining.

\section{Quantitative real-time PCR (qPCR)}

The cDNA templates were synthesized as mentioned previously. qPCR reactions were performed with a BioRad CFX system using the iQ SYBR Green supermix kit (Bio$\mathrm{Rad}$ ) according to the manufacturer's instructions. PCR procedure was: pre-incubation at $95^{\circ} \mathrm{C}$ for $5 \mathrm{~min}$ followed by 40 cycles of denaturation at $95^{\circ} \mathrm{C}$ for $15 \mathrm{~s}$, annealing at $60{ }^{\circ} \mathrm{C}$ for $15 \mathrm{~s}$, and extension at $72{ }^{\circ} \mathrm{C}$ for $15 \mathrm{~s}$. The Actin 1 and elongation factor 1 ( EF1) (Long et al., 2010; Liang et $a l ., 2012)$ were used as internal controls to quantify the relative transcript level. The sequence of EFl was firstly obtained as mentioned above. The primers used for qPCR analyses are listed in Table 1 . The amplification specificity was checked with a heat-dissociation protocol (melting curves in the $65-95^{\circ} \mathrm{C}$ range) as a final step of the PCR. All primer pairs showed a single peak on the melting curve (Figure S2). For each of the independent experiments, the target and internal control were amplified in separate wells in triplicate. The $\mathrm{Cq}$ values were determined automatically by BioRad CFX manager 2.1 (BioRad) and the mean Cq of triplicates was used to calculate the relative level of gene expression by using the $2^{-\Delta \Delta \mathrm{CT}}$ method (Livak and Schmit- tgen, 2001). The final expression data are presented as means from three independent experiments.

\section{Data analysis}

Means and standard deviations (SD) of the expression data were calculated by using SPSS package version 16.0 (SPSS Inc.). Data were analyzed with one-way analysis of variance (ANOVA) and the mean differences were compared by the least significant difference (LSD) test.

\section{Results}

\section{Cloning of a $D R E B 1$ gene from Iceland poppy}

As no genomic resource for the Iceland poppy is available, a pair of degenerate primers, DREB1-F1 and DREB-F1, was designed based on the conserved AP2/ERF domains of DREB1s from several dicot species (data not shown). By RT-PCR, a fragment of 204 bp was obtained (Figure S3a) containing a AP2/ERF domain and showing high degree of sequence similarity to known $D R E B 1 / C B F S$ (Data not shown). Based on this sequence, further 3'RACE and 5'RACE were performed and a $767 \mathrm{bp}$ and a $470 \mathrm{bp}$ fragment were obtained, respectively (Figure S3b,c). The three fragments were assembled to a $1035 \mathrm{bp}$ sequence. The sequence contains a continuous open reading frame (ORF) with an initiation codon (ATG) and a stop codon (TGA). A pair of primers was further designed to validate the obtained sequences by RT-PCR and genomic PCR (Figure $\mathrm{S} 3 \mathrm{c})$. The sequencing showed identical results as the assembled primer.

\section{Sequence analyses}

The ORF of the obtained sequence is $699 \mathrm{bp}$ long and encodes a deduced protein of 232 amino acids, with 26.3 $\mathrm{kDa}$ molecular weight and isoelectric point of 5.33 (Figure 1a). BLAST search against Arabidopsis whole genome protein database (TAIR 10) was performed, which indicated that the obtained sequence showed the highest homology to six TFs of A-1 group of Arabidopsis DREB subfamily. Homology modeling indicated that the 3D structures of the obtained sequence and the four AtDREB1 proteins contained a conserved AP2/ERF domain with a typical three-dimensional conformation of three antiparallel $\beta$ sheets followed by a parallel $\alpha$-helix (Figure 1b). These results suggested that the obtained gene belongs to DREB1 group of DREB TF subfamily, designated PnDREB1 (Table 2) (Accession No. KU500634). BLASTP search against the NCBI nr protein database indicated that PnDREB1 shares the highest sequence identity of only 58\% (99\% query cover and $\mathrm{E}$ value $=2 \mathrm{e}-80$ ) to $\mathrm{CBF} 1$ of Morus alba var. multicaulis (GenBank accession number AFQ59977.1), indicating that PnDREB1 is a novel DREB1 gene. 
a

GAAAAATTACTTTACAATTACAAAGTACCAGAATCAATCAATCGAACAGTTCTCAACAGTTATCATCTACTAAAT TGAA 79

ATGGATATGTTTTGTTACAACCAGCTACAACAGAATCAGTACACAGATTCGAGATCACCGGTATCTGATTCGAGT $\begin{array}{lllllllllllllllllllllllll}M & D & M & F & C & Y & N & Q & L & Q & Q & N & Q & Y & T & D & S & R & S & P & V & S & D & S & S\end{array}$

TTGAGTAATCGGAATACGTTTTCAGATGAAGAGATTCAATTAGCATCGGATAAACCGAAACGGAAAGCAGGAAGA $\begin{array}{lllllllllllllllllllllllll}\mathrm{L} & \mathrm{S} & \mathrm{N} & \mathrm{R} & \mathrm{N} & \mathrm{T} & \mathrm{F} & \mathrm{S} & \mathrm{D} & \mathrm{E} & \mathrm{E} & \mathrm{I} & \mathrm{Q} & \mathrm{L} & \mathrm{A} & \mathrm{S} & \mathrm{D} & \mathrm{K} & \mathrm{P} & \mathrm{K} & \mathrm{R} & \mathrm{K} & \mathrm{A} & \mathrm{G} & \mathrm{R}\end{array}$

ACGAAGTTTCGGGAGACGAGACATCCGGTTTACAGAGGAGTGAGGCAAAGGAACAATGATAAATGGGTATGTGAA \begin{tabular}{lllllllllllllllllllllllll}
$\mathrm{T}$ & $\mathrm{K}$ & $\mathrm{F}$ & $\mathrm{R}$ & $\mathrm{E}$ & $\mathrm{T}$ & $\mathrm{R}$ & $\mathrm{H}$ & $\mathrm{P}$ & $\mathrm{V}$ & $\mathrm{Y}$ & $\mathrm{R}$ & $\mathrm{G}$ & $\mathrm{V}$ & $\mathrm{R}$ & $\mathrm{Q}$ & $\mathrm{R}$ & $\mathrm{N}$ & $\mathrm{N}$ & $\mathrm{D}$ & $\mathrm{K}$ & $\mathrm{W}$ & $\mathrm{V}$ & $\mathrm{C}$ & $\mathrm{E}$ \\
\hline
\end{tabular} GTAAGAGAACCAAATAAGAAAACAAGGATATGGTTAGGTACTTTTGCTACACCAGAAATGGCTGCTCGTGCACAT \begin{tabular}{lllllllllllllllllllllllllll}
$\mathrm{V}$ & $\mathrm{R}$ & $\mathrm{E}$ & $\mathrm{P}$ & $\mathrm{N}$ & $\mathrm{K}$ & $\mathrm{K}$ & $\mathrm{T}$ & $\mathrm{R}$ & $\mathrm{I}$ & $\mathrm{W}$ & $\mathrm{L}$ & $\mathrm{G}$ & $\mathrm{T}$ & $\mathrm{F}$ & $\mathrm{A}$ & $\mathrm{T}$ & $\mathrm{P}$ & $\mathrm{E}$ & $\mathrm{M}$ & $\mathrm{A}$ & $\mathrm{A}$ & $\mathrm{R}$ & $\mathrm{A}$ & $\mathrm{H}$ \\
\hline
\end{tabular} GATGTTGCAGCAATGGCATTCAGAGGTAGATCAGCTTGTCTTAATTTCGCTGATTCCGTCTGGAGATTGCCTGTA $\begin{array}{lllllllllllllllllllllllllll}\mathrm{D} & \mathrm{V} & \mathrm{A} & \mathrm{A} & \mathrm{M} & \mathrm{A} & \mathrm{F} & \mathrm{R} & \mathrm{G} & \mathrm{R} & \mathrm{S} & \mathrm{A} & \mathrm{C} & \mathrm{L} & \mathrm{N} & \mathrm{F} & \mathrm{A} & \mathrm{D} & \mathrm{S} & \mathrm{V} & \mathrm{W} & \mathrm{R} & \mathrm{L} & \mathrm{P} & \mathrm{V}\end{array}$

CCTGTTTCTTCTGATCCTGATGATATTAGAAAAGCTGCAGTTGAAGCTGCCAATGCATTTCAACAGTCTGATTTA $\begin{array}{llllllllllllllllllllllllll}\mathrm{P} & \mathrm{V} & \mathrm{S} & \mathrm{S} & \mathrm{D} & \mathrm{P} & \mathrm{D} & \mathrm{D} & \mathrm{I} & \mathrm{R} & \mathrm{K} & \mathrm{A} & \mathrm{A} & \mathrm{V} & \mathrm{E} & \mathrm{A} & \mathrm{A} & \mathrm{N} & \mathrm{A} & \mathrm{F} & \mathrm{Q} & \mathrm{Q} & \mathrm{S} & \mathrm{D} & \mathrm{L}\end{array}$

ACTGATGAGAATAACAATTCGGGGAATTCGGAGAATTTGAATTCGATGATTTCGTTGTCGCCGGTTAGTCCGATG $\begin{array}{lllllllllllllllllllllllll}\mathrm{T} & \mathrm{D} & \mathrm{E} & \mathrm{N} & \mathrm{N} & \mathrm{N} & \mathrm{S} & \mathrm{G} & \mathrm{N} & \mathrm{S} & \mathrm{E} & \mathrm{N} & \mathrm{L} & \mathrm{N} & \mathrm{S} & \mathrm{M} & \mathrm{I} & \mathrm{S} & \mathrm{L} & \mathrm{S} & \mathrm{P} & \mathrm{V} & \mathrm{S} & \mathrm{P} & \mathrm{M}\end{array}$

ATTTCACAGGAGAAAGTGTTTTATATGGATGAAGAAGCTGAATTTGGAATGCCAAGGTTTTATGCTGATATGGCG $\begin{array}{llllllllllllllllllllllllll}I & S & Q & E & K & V & F & Y & M & D & E & E & A & E & F & G & M & P & R & F & Y & A & D & M & A\end{array}$

GAAGGATTGTTACTGTCACCACCTCCTTCAAGAGGATTCAGTTGGGATGATATGGACAGTAATCATGCTGAAGTG $\begin{array}{llllllllllllllllllllllllllll} & \text { E } & G & L & L & L & S & P & P & P & S & R & G & F & S & W & D & D & M & D & S & N & H & A & E & V\end{array}$

TCACTCTGGAGTTACTCCATCTGA

S L W $S$ Y S I *

AATTTTTACCTTTGGGTAAAAAATTCAGAGTCCAACTTATCAATATAGTGAGTACATATATTATTGTACTTGAAT TTTGAAGTCATGTAAAAGGGGTATTTGACGAATACTCTGCCTTTTGGTTTTTAGAGTCTTAGGTATATATATCAA CTAGTACTACTTAGTCATGTACAGTAAAAAAATTCAAGTTTGTAAGAGGGAATTCACAGGATCAATAAAGAGTTA GAATTCAGAAAAAAAAAAAAAAAAAAAAAAA 1035

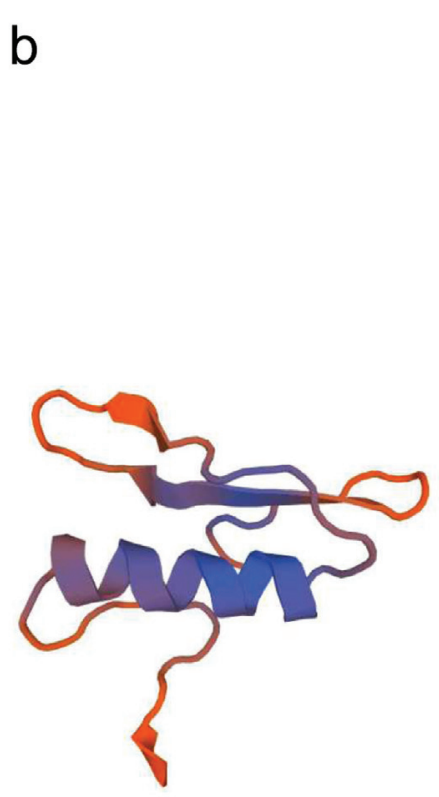

PnDREB1

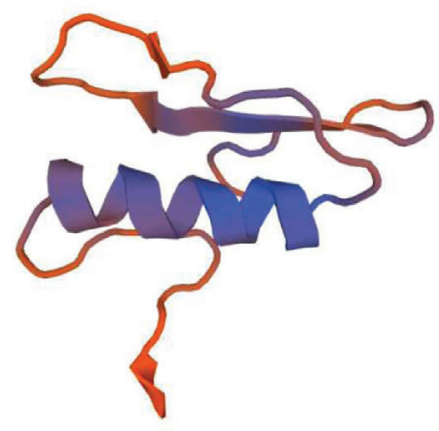

AtDREB1A/CBF3

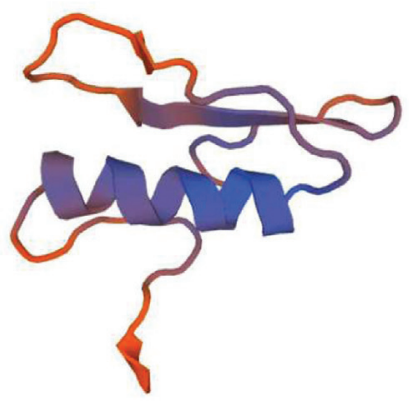

AtDREB1B/CBF1

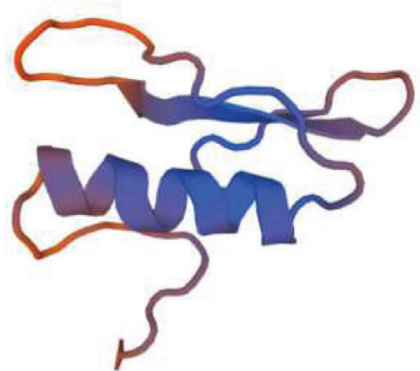

AtDREB1C/CBF2

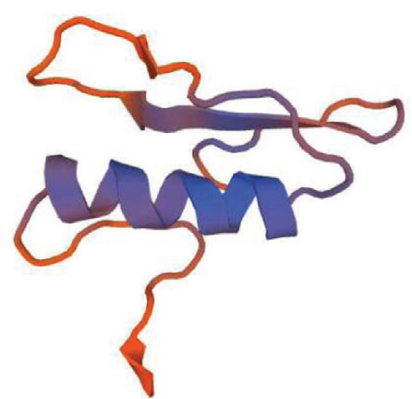

AtDREB1D/CBF4

Figure 1 - Sequences of PnDREB1 (a) and comparison of 3D structures of four DREB1 proteins of Arabidopsis (b). The AP2/ERF domain is underlined. 
Table 2 - Homology of PnDREB1 to DREB1s in Arabidopsis.

\begin{tabular}{llll}
\hline Gene ID & Description & Function & E value \\
\hline AT5G51990.1 & DREB1D/CBF4 & Response to drought stress and ABA & $2 \mathrm{e}-50$ \\
AT4G25470.1 & DREB1C/CBF2 & Response to low temperature and circadian rhythm & $4 \mathrm{e}-46$ \\
AT4G25490.1 & DREB1B/CBF1 & Response to low temperature & $2 \mathrm{e}-45$ \\
AT4G25480.1 & DREB1A/CBF3 & Response to low temperature & $2 \mathrm{e}-44$ \\
AT1G12610.1 & DREB/DDF1 & Induce GA biosynthesis under salt stress & $4 \mathrm{e}-38$ \\
AT1G63030.1 & DREB/DDF2 & Reduce ABA biosynthesis by overexpression & $5 \mathrm{e}-37$ \\
\hline
\end{tabular}

To evaluate the structural similarity, motif identification and comparison were performed between the PnDREB1 and 35 known DREB1 from 33 different dicots or monocots species (Figure 2). PnDREB1 contains eight motifs, which are similar to those of 12 DREB1s from 10 species, such as Arabidopsis, M. alba, Manihot esculenta, Avicennia marina, etc. Motif 1 and motif 2 are shared by all DREB1 proteins, covering the whole AP2/ERF domain. Motifs $3 \sim 7$ are also common, present in $\sim 79.5 \%$ to $\sim 83.3 \%$ of the DREB1s analyzed, indicating that they might be functionally important to the DREB1s.

\section{Comparison of AP2/ERF domain and phylogenetic analysis}

The AP2/ERF domain sequences were retrieved from the 36 DREB1s as described above. Most of the sequences are composed by 58 residues, with three exceptions, and 2 peptides containing 59 and 60 residues. The multiple sequence alignment showed that the AP2/ERF domain of PnDREB1 is highly homologous to other 35 DREB1s from divergent species (Figure 3a). A total of 19 amino acids are identical among 36 proteins, including motif YRGVR and WLG, and some other residues, such as Arg-8, Trp-13, etc. These conserved residues mainly lie in the regions comprising three $\beta$-sheets and one $\alpha$-helix, which are structurally important. The residues outside these regions are rather divergent. The drawn domain logo showed the variability and conservation of each residue in AP2/ERF domain of DREB1s (Figure 3b).

The phylogenetic tree constructed based on the alignment of amino acid sequences of AP2/ERF domain (Figure 4) showed that PnDREB1 was clustered with DREB1s of G. max, and species of Medicago, Prunus, and Vaccinium, and significantly separated from those of monocots.

\section{Spatial expression patterns, freezing and phytohormone-induced responses}

The spatial expression of PnDREB1 indicated that, under normal conditions, the expression of PnDREBI could be detected in all analyzed tissues, including petal, pedicel, leaf, petiole, and root (Figure 5a). The root exhibited higher expression levels than other tissues.
We further investigated the dynamic changes of $P n D R E B 1$ expression levels under freezing treatment $(0$ ${ }^{\circ} \mathrm{C}$ ) by qPCR. In leaves, the expression level of PnDREB 1 was very low at beginning of the treatment (Figure 5b). After $2 \mathrm{~h}$, the expression level significantly increased and reached a peak at $8 \mathrm{~h}$; after $12 \mathrm{~h}$, the expression decreased to similar levels as the initial stage of treatment. In roots, the expression level was slightly higher than those in leaves at the initial stage. After $2 \mathrm{~h}$, the level decreased and remained low until $12 \mathrm{~h}$, when it increased to a slightly higher levels than those before treatment (Figure 5c). We also evaluated the expression levels in another Iceland poppy variety (WL) with lower freezing tolerance. WL showed similar patterns in roots. However, in leaves, it increased slower and exhibited a significantly lower peak expression than CB (Figure 5b).

The responses of PnDREB1 to the phytohormones gibberellic acid (GA) and abscisic acid (ABA) were investigated by qPCR. Under freezing temperature, the $\mathrm{GA}_{3}-$ treated plants exhibited lower expression levels compared to non-GA $\mathrm{A}_{3}$-treated plants (Figure $5 \mathrm{~d}$ ). The ABA treatment was performed under hydroponic growth condition. In leaves, the expression level of PnDREB 1 decreased to the lowest level at $1 \mathrm{~h}$; one hour later, it gradually increased and reached a peak at $4 \mathrm{~h}$; at $12 \mathrm{~h}$, it decreased to a similar level as $1 \mathrm{~h}$. At all time points, levels were lower than that of the control (untreated) (Figure 5e). In roots, the expression level intensely increased $\sim 26$-fold that of control within 0.5 h. After that, it was down-regulated to the lowest level of about $\sim 7$-fold at $2 \mathrm{~h}$ and then was up-regulated again $\sim 20$-fold at $12 \mathrm{~h}$ (Figure 5f).

\section{Discussion}

DREB1 has been characterized as an important regulator of cold response among a spectrum of plant species. In the present study, the cDNA and genomic sequences of a novel DREB1 TF, PnDREB1, with a high sequence similarity and similar predicted 3D structure to DREB1s of Arabidopsis, was isolated from the boreal ornamental plant Iceland poppy. Phylogenetic analysis indicated that the AP2 domain of PnDREB1 is close to those of G. max, and Medicago, Prunus, and Vaccinium species. 


\section{AAS00621.1_Eutrema_salsugineum \\ AT4G25490.1_Arabidopsis \\ AFA50331.1_Manihot_esculenta \\ AFQ59977.1_Morus_alba \\ AT4G25480.1_Arabidopsis \\ AT4G25470.1 Arabidonsis \\ PnDREB1_Papaver_nudicaule}

AFU81299.1_Aegiceras_corniculatum

AHH86059.1_Avicennia_marina

AFU81298.1_Bruguiera_gymnorhiza

XM010257243.1 Nelumbo nucifera

AHI59143.1_Populus_davidiana

ACE73693.1_Nicotiana_tabacum

CBZ41764.1_Glycine_max

DQ118521.1_Capsicum_annuum

ABV65907.1_Fragaria_xananassa

AT5G51990.1_Arabidopsis

AHJ08667.1_Kandelia_candel

FJ605122.1_Chrysanthemum_x_morifolium

AHI59150.1_Cichorium_intybus

BAD27123.1_Prunus_avium

ACF94686.1 Prunus canescens x Prunus cerasus 4.6e-121

ACR39335.1_Vaccinium_vitisidaea

AFC89542.1 Vaccinium uliqinosum

AGR40676.1 Medicaqo truncatula

ABY78835.1_Medicago_sativa

ADY68770.1_Adonis_amurensis

AIZ97485.1_Deschampsia_antarctica

AEM63548.1_Solanum tuberosum

ABJ09421.1_Aloe_vera

AAL40870.1_Oryza_sativa

AAY25517.1_Hordeum_vulgare_subsp._vulgare

ACV42429.1_Zoysia_japonica

ACF98541.1_Phyllostachys_edulis

ABO48362.1_Populus_trichocarpa

ABR53728.1_Cymbidium_insigne

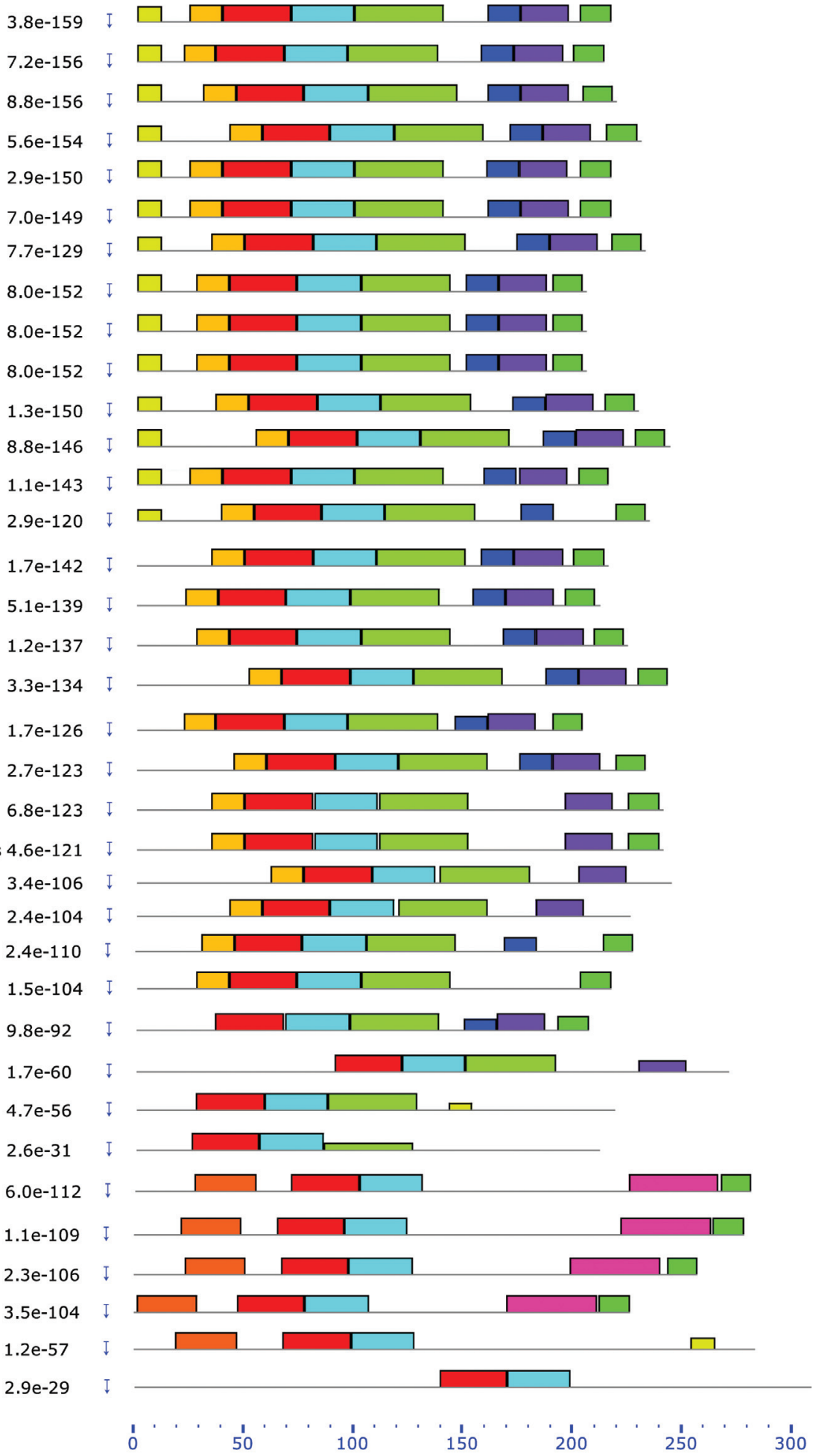

$\begin{array}{lllll}50 & 100 & 150 & 200 & 250\end{array}$

Motif $1 \square$ Motif $2 \square$ Motif $3 \square$ Motif $4 \square$ Motif $5 \square$ Motif $6 \square$ Motif $7 \square$ Motif $8 \square$ Motif $9 \square$ Motif 10

Figure 2 - Comparison of protein motifs of 35 DREB1s from diverse dicot and monocot species. The PnDREB1 is boxed.

A motif is a pattern common to a set of nucleic or amino acid subsequences which share some biological property (Timothy and Charles, 1994). Thus, the motif compositions and distributions among a set of sequences reflect, to a certain extent, the structural and functional similarity. We compared the motifs of PnDREB1 to 35 known DREB1s from 33 species (Figure 2 and Figure S4). All shared high conserved AP2/ERF domain, in which 19 residues are con- 
a

\begin{tabular}{ll} 
Accession No. & \multicolumn{1}{c}{ Organism } \\
PnDREB1 & Papaver nudicaule \\
AT5G51990.1 & A.thaliana \\
AT4G25470.1 & A. thaliana \\
AT4G25490.1 & A. thaliana \\
AT4G25480.1 & A.thaliana \\
DQ118521.1 & Capsicum annum \\
AFU81298.1 & Bruguiera gymnorhiza \\
AFA50331.1 & Manihot esculenta \\
AHI59150.1 & Cichorium intybus \\
ACE73693.1 & Nicotiana tabacum \\
AHH86059.1 & Avicennia marina \\
FJ605122.1 & Chrysanthemum $x$ morifolium \\
AHJ08667.1 & Kandelia candel \\
AAS00621.1 & Eutrema salsugineum \\
AHI59143.1 & Populus davidiana \\
XM010257243.1 & Nelumbo nucifera \\
AFU81299.1 & Aegiceras corniculatum \\
CBZ41764.1 & Glycine max \\
AGR40676.1 & Medicago truncatula \\
ABY78835.1 & Medicago sativa \\
ABV65907.1 & Fragaria xananassa \\
ACF94686.1 & Prunus canescens $x$ Prunus cerasus \\
BAD27123.1 & Prunus avium \\
AFQ59977.1 & Morus alba \\
ADY68770.1 & Adonis amurensis \\
AIZ97485.1 & Deschampsia antarctica \\
ABJ09421.1 & Aloe vera \\
ABR53728.1 & Cymbidium insigne \\
ACF98541.1 & Phyllostachys edulis \\
ABO48362.1 & Populus trichocarpa \\
ACV42429.1 & Zoysia japonica \\
&
\end{tabular}

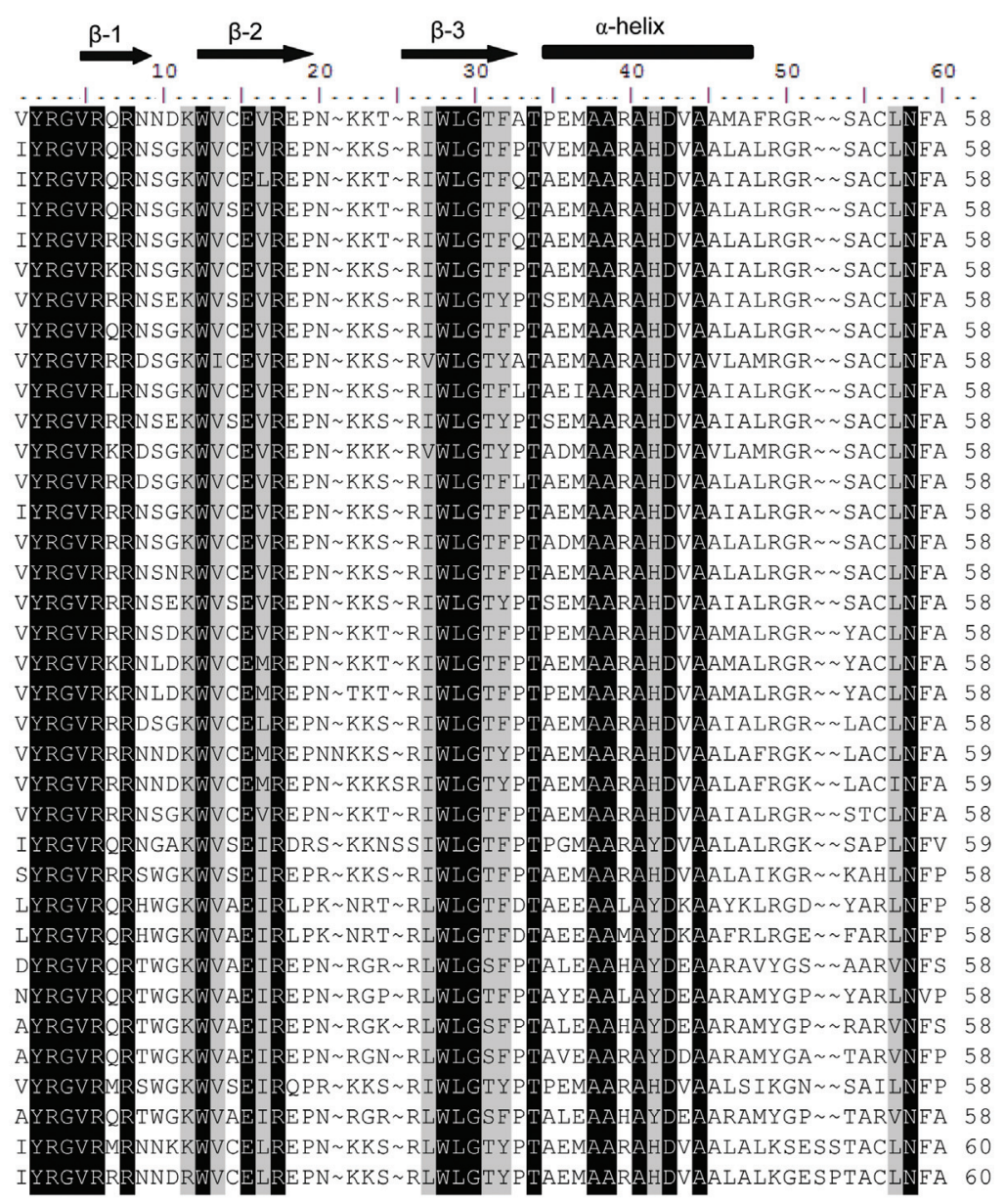

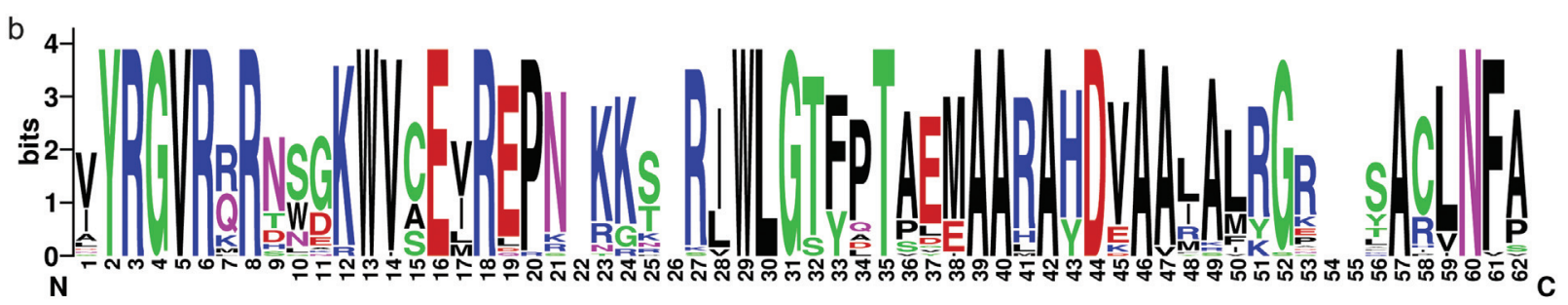

Figure 3 - Comparison of deduced amino acid sequences of AP2/ERF domain of 35 DREB1s from diverse dicot and monocot species. a, multiple alignment of amino acid sequences of AP2/ERF domain. Black shading indicates identical residues; gray shading indicates highly conserved residues. b, Motif logo drawn based on the multiple alignment of amino acid sequences of AP2/ERF domain. The overall height of the stack indicates the sequence conservation at that position, while the height of symbols within the stack indicates the relative frequency of each amino at that position.

served in $\sim 95 \%$ of DREB1s. Previous studies showed that the 14th valine (V14) and 19th glutamic acid (E19), especially the former, of the AP2/ERF domain, are conserved among the DREB protein (Liu et al., 1998). They are distinguished from alanine and aspartic acid of ERF protein and are important for its binding specificity (Sakuma et al., 2002). PnDERB1 contained the same conserved V14 and E19 at these two positions, indicating that it might possess similar binding patterns as DREB1s of Arabidopsis to DRE/CRT motif in the promoter of some downstream stress-induced genes.
Nakano et al. (2006) reported that some motifs outside the AP2/ERF domain are also conserved for DREB1 proteins. Motif CMIII-1 is common for DREB1s; CMIII-2 and CMIII-4 are conserved in C-terminal region, and CMIII-4, also known as LWSY motifs, is conserved in rice and Arabidopsis and has been shown to function as a transactivation domain (Wang et al., 2005). The CMIII-3, separated by AP2/ERF domain, is also conserved and was reported in other studies (Jaglo et al., 2001; Haake et al., 2002). Despite of different methods used for motif identification, PnDREB1 was found to contain all of these motifs: motif 3 covers CMIII-1; motif 5 and part of motif 3 is 


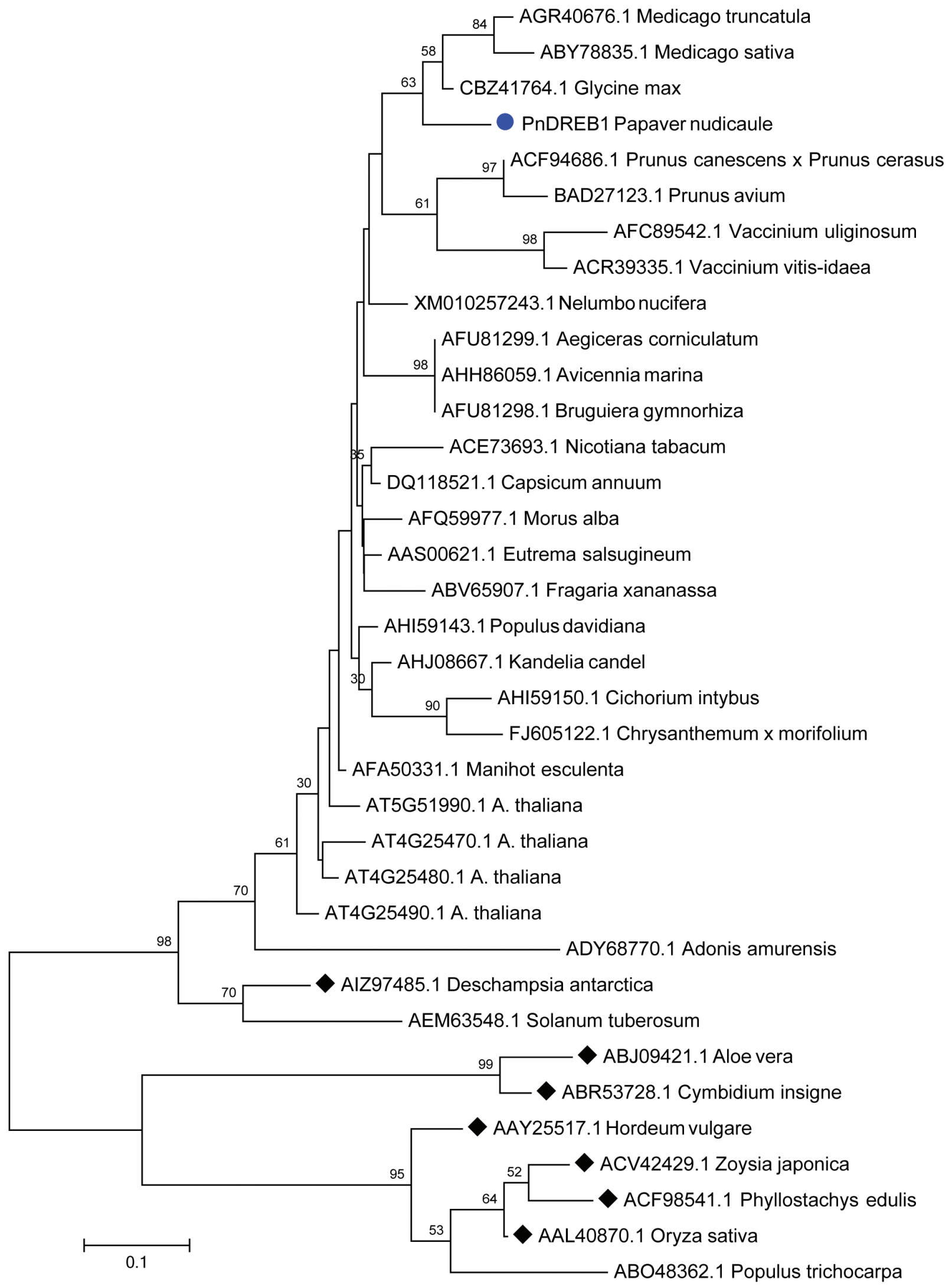

Figure 4 - Phylogenetic tree based on the deduced amino acid sequences of AP2/ERF domain of 35 DREB1s. The tree is constructed by maximum likelihood method with 1000 bootstrap replications. Before tree reconstruction, a model test was performed. The model with the lowest BIC scores (Bayesian Information Criterion), the Jones-Taylor-Thornton (JTT) model with parameters of Gamma distribution $(+\mathrm{G})$ with 5 rate categories for Rates and Patterns were chosen. Diamonds indicate the monocot species. 
a
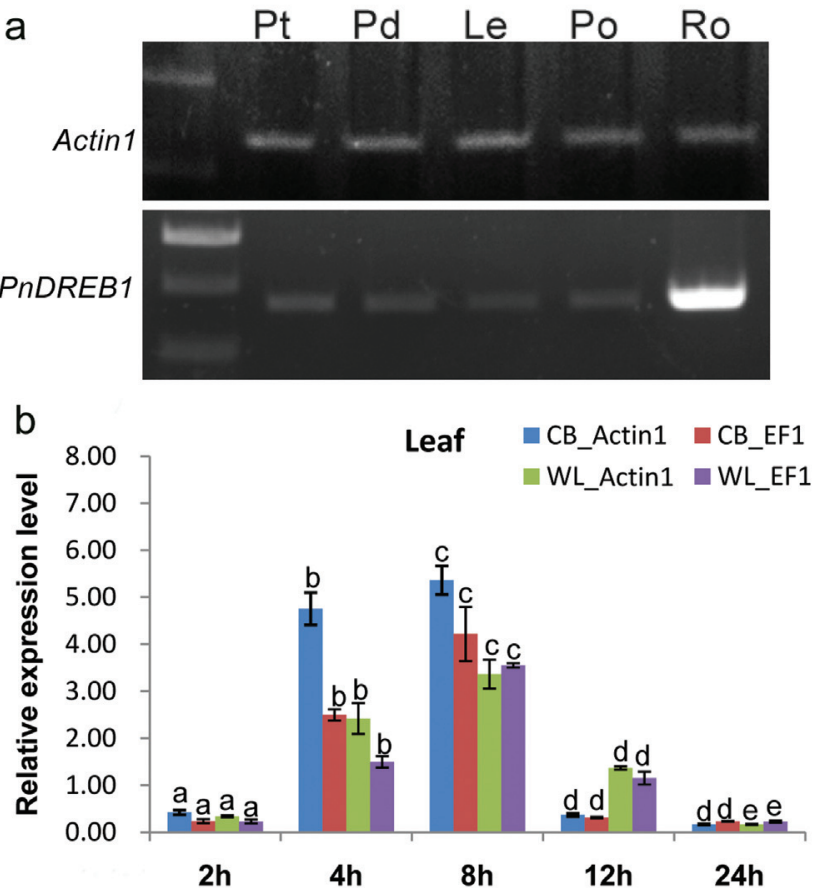

C

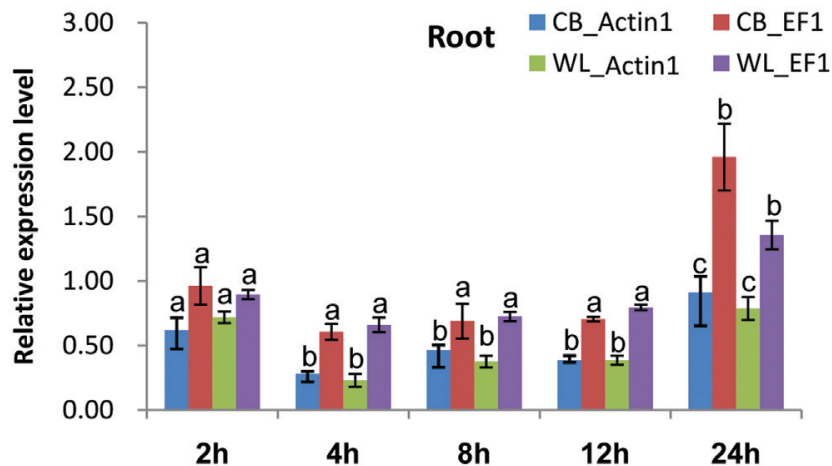

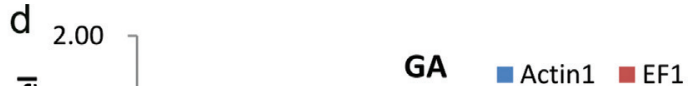

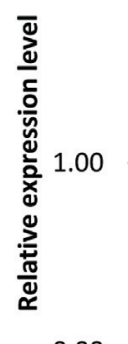

e

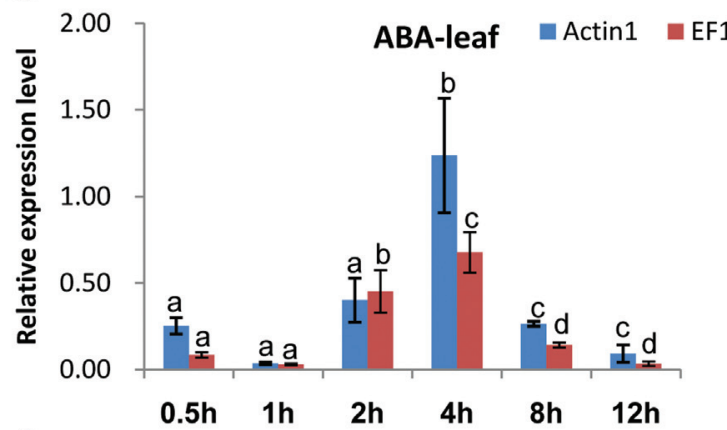

f

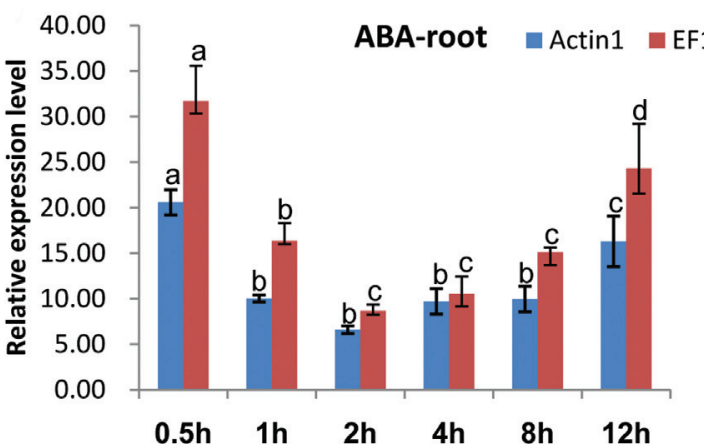

Figure 5 - Expression profiles of PnDREB1. (a), Semi quantitative RT-PCR analysis of spatial expression patterns in petal (Pt), pedicel (Pd), leaf (Le), petiole (Po), and root (Ro); b and c) show qPCR analysis results; relative expression levels of PnDREB1 at different time points (x-axis) of freezing treatment in leaf and root, respectively, in fold-change (y-axis); d) qPCR analysis results showing changes of relative expression levels of gibberellins acid$\left(\mathrm{GA}_{3}, 80 \mu \mathrm{M}\right)$ treated plants under same treatment as those of $\left.\mathrm{b}\right)$; e and $\mathrm{f}$ ) fold changes of relative expression levels under treatment of $100 \mu \mathrm{M}$ abscisic acid (ABA). CB, Champagne Bubbles; WL, Wonderland. Data are shown as means \pm SD (n=3). Actin1 and EF1 were used as internal controls. Different lowercase letters on rectangular columns indicate significant differences to that of previous time point $(\mathrm{P}<0.05)$.

equivalent to CMIII-3; the adjacent motif 7 and motif 4 are approximate to the CMIII-2, and CMIII-4 is involved in motif 6. These results indicated that PnDREB1 might be an active stress-induced DREB1 protein.

Our further investigation of dynamic expression changes under freezing treatment showed that PnDREB1 was induced by freezing both in leaves and roots though in different patterns. The expression level in leaves was quickly upregulated and reached peak level at $8 \mathrm{~h}$. These results are similar to some reports in other species (Stockinger et al., 1997; Liu et al., 1998; Qin et al., 2004; Huang et al., 2007; Shan et al., 2007; Kidokoro et al., 2015). Interestingly, freezing-induced expression in leaves could be sup- pressed by exogenous $\mathrm{GA}_{3}$. This phenomenon was also found in cotton, indicating that it may play an important role in GA signaling (Shan et al., 2007). Our comparative analysis also indicated that expression of PnDREB1 in the $\mathrm{CB}$ variety with high freezing tolerance increases faster and accumulates to higher levels than those in WL variety with lower freezing tolerance. The difference in freezing inductive accumulation of PnDREB1 transcription level might partly contribute to their different performance under freezing tolerance.

In roots, $P n D R E B 1$ exhibits higher expression levels than those of other tissues under normal condition. However, in mangrove Aegiceras corniculatum, the highest expression was detected in leaves (Peng et al., 2015). This 
suggests that DREB1 may function diversely in plant development in different species. Under freezing stress, PnDREB1 was induced gradually and exhibited first a down- and then up-regulated pattern, which seems to be complementary to that in leaves (Figures $5 \mathrm{~b}$ and c). Few reports individually addressed the expression changes in roots under stress. However, we speculated that this might be due to two reasons: first, our freezing treatment was performed under hydroponic condition, by which the leaves might perceive freezing stress more quickly than roots; second, there might exist a balance PnDREB1 expression between roots and leaves.

$\mathrm{ABA}$ is an important plant hormone that plays a regulatory role in many development processes in plants, as well as in the activation of stress-responsive genes (Agarwal and Jha, 2010). Previous studies in Arabidopsis showed that $D R E B 1 D / C B F 4$ is rapidly induced by drought and ABA but not by cold stress (Haake et al., 2002), whereas DREB1B/CBF1, DREB1A/CBF3, and DREB1C/ $C B F 2$ are strongly and transiently induced by low temperature stresses but not by ABA or dehydration (Gilmour et al., 1998; Medina et al., 1999). However, these different results come from diverse plant species. PNDREB1 of Arachis hypogaea was strongly upregulated by treatments with low temperature, and also responded to dehydration (Zhang et al., 2009); PpDBF1 of Physcomitrella patens was simultaneously induced by $\mathrm{NaCl}$, cold, drought, and $\mathrm{ABA}$ (Liu et al., 2007). The results obtained in this study showed that besides freezing treatment, $P n D R E B 1$ is also rapidly induced by ABA, especially in roots, suggesting that $P n D R E B 1$ is possibly involved in other abiotic stress responses, such as drought and $\mathrm{NaCl}$. Further research is needed to clarify this speculation.

\section{Acknowledgments}

We are grateful to Institute of Ecology and Forestry of Sichuan Agricultural University for their helpful assistance in the experiments. This work is financially supported by the Education Department of Sichuan Province, China (No. 15ZA0014).

\section{References}

Agarwal PK and Jha B (2010) Transcription factors in plants and ABA dependent and independent abiotic stress signalling. Biol Plantarum 54:201-212.

Biasini M, Bienert S, Waterhouse A, Arnold K, Studer G, Schmidt T, Kiefer F, Cassarino TG, Bertoni M, Bordoli L, et al. (2014) SWISS-MODEL: Modelling protein tertiary and quaternary structure using evolutionary information. $\mathrm{Nu}$ cleic Acids Res 42:W252-W258.

Crooks GE, Hon G, Chandonia JM and Brenner SE (2004) WebLogo: A sequence logo generator. Genome Res 14:1188-1190.
Dubouzet JG, Sakuma Y, Ito Y, Kasuga M, Dubouzet EG, Miura S, Seki M, Shinozaki K and Yamaguchi-Shinozaki K (2003) OsDREB genes in rice, Oryza sativa L., encode transcription activators that function in drought-, high-salt- and coldresponsive gene expression. Plant J 33:751-763.

Edgar RC (2004) MUSCLE: Multiple sequence alignment with high accuracy and high throughput. Nucleic Acids Res 32:1792-1797.

Fowler S and Thomashow MF (2002) Arabidopsis transcriptome profiling indicates that multiple regulatory pathways are activated during cold acclimation in addition to the CBF cold response pathway. Plant Cell 14:1675-1690.

Gilmour SJ, Zarka DG, Stockinger EJ, Salazar MP, Houghton JM and Thomashow MF (1998) Low temperature regulation of the Arabidopsis CBF family of AP2 transcriptional activators as an early step in cold-induced COR gene expression. Plant J 16:433-442.

Haake V, Cook D, Riechmann JL, Pineda O, Thomashow MF and Zhang JZ (2002) Transcription factor CBF4 is a regulator of drought adaptation in Arabidopsis. Plant Physiol 130:639648.

Hall TA (1999) BioEdit: A user-friendly biological sequence alignment editor and analysis program for Windows 95/98/NT. Nucleic Acids Symp Ser 41:95-98.

Hannah MA, Wiese D, Freund S, Fiehn O, Heyer AG and Hincha DK (2006) Natural genetic variation of freezing tolerance in Arabidopsis. Plant Physiol 142:98-112.

Hong B, Tong Z, Li QH, Ma C, Kasuga M, Yamaguchi-Shinozaki $\mathrm{K}$ and Gao JP (2006a) Regeneration and transformation through somatic embryogenesis, and determination of cold stress tolerance in ground cover Chrysanthemum cv. Fall color. Sci Agric Sin 39:1443-1450.

Hong B, Tong Z, Ma N, Kasuga M, Yamaguchi-Shinozaki K and Gao JP (2006b) Expression of Arabidopsis DREB1A gene in transgenic chrysanthemum enhances tolerance to low temperature. J Hortic Sci Biot 81:1002-1008.

Hong B, Tong Z, Ma N, Li JK, Kasuga M, Yamaguchi-Shinozaki $\mathrm{K}$ and Gao JP (2006c) Heterologous expression of the AtDREB1A gene in chrysanthemum increases drought and salt stress tolerance. Sci China C Life Sci 49:436-445.

Hong JP and Kim WT (2005) Isolation and functional characterization of the Ca-DREBLP1 gene encoding a dehydrationresponsive element binding-factor-like protein 1 in hot pepper (Capsicum annuum L. cv Pukang). Planta 220:875-888.

Huang B, Jin L and Liu J (2007) Molecular cloning and functional characterization of a DREB1/CBF-like gene (GhDREB1L) from cotton. Sci China Ser C-Life Sci 50:7-14.

Istatkova R, Philipov S, Yadamsurenghiin GO, Samdan J and Dangaa S (2008) Alkaloids from Papaver nudicaule L. Nat Prod Res 22:607-611.

Ito Y, Katsura K, Maruyama K, Taji T, Kobayashi M, Seki M, Shinozaki K and Yamaguchi-Shinozaki K (2006) Functional analysis of rice DREB1/CBF-type transcription factors involved in cold-responsive gene expression in transgenic rice. Plant Cell Physiol 47:141-153.

Jaglo KR, Kleff S, Amundsen KL, Zhang X, Haake V, Zhang JZ, Deits $\mathrm{T}$ and Thomashow MF (2001) Components of the Arabidopsis C-repeat/dehydration-responsive element binding factor cold-response pathway are conserved in Brassica napus and other plant species. Plant Physiol 127:910-917. 
Kasuga M, Miura S, Shinozaki K and Yamaguchi-Shinozaki K (2004) A combination of the Arabidopsis DREB1A gene and stress-inducible RD29A promoter improved drought and low-temperature stress tolerance in tobacco by gene transfer. Plant Cell Physiol 45:346-350.

Kidokoro S, Watanabe K, Ohori T, Moriwaki T, Maruyama K, Mizoi J, Myint PSHN, Fujita Y, Sekita S, Shinozaki K, et al. (2015) Soybean DREB1/CBF-type transcription factors function in heat and drought as well as cold stress-responsive gene expression. Plant J 81:505-518.

Lata C and Prasad M (2011) Role of DREBs in regulation of abiotic stress responses in plants. J Exp Bot 62:4731-4748.

Lata C, Bhutty S, Bahadur RP, Majee M and Prasad M (2011) Association of an SNP in a novel DREB2-like gene SiDREB2 with stress tolerance in foxtail millet (Setaria italica L.). J Exp Bot 62:3387-3401.

Letunic I, Doerks T and Bork P (2012) SMART 7: Recent updates to the protein domain annotation resource. Nucleic Acids Res 40:302-305.

Liang J, Deng G, Long H, Pan Z, Wang C, Cai P, Xu D, Nima Z-X and Yu M (2012) Virus-induced silencing of genes encoding LEA protein in Tibetan hulless barley (Hordeum vulgare ssp. vulgare) and their relationship to drought tolerance. Mol Breeding 30:441-451.

Licausi F, Ohme-Takagi M and Perata P (2013) APETALA2/Ethylene Responsive Factor (AP2/ERF) transcription factors: Mediators of stress responses and developmental programs. New Phytol 199:639-649.

Liu N, Zhong N, Wang G, Li L, Liu X, He Y and Xia G (2007) Cloning and functional characterization of $P p D B F 1$ gene encoding a DRE binding transcription factor from Physcomitrella patens. Planta 226:827-838.

Liu Q, Kasuga M, Sakuma Y, Abe H, Miura S, YamaguchiShinozaki K and Shinozaki K (1998) Two transcription factors, DREB1 and DREB2 with an EREBP/AP2 DNA binding domain separate two cellular signal transduction pathways in drought and low-temperature-responsive gene expression, respectively, in Arabidopsis. Plant Cell 10:1391-1406.

Livak KJ and Schmittgen TD (2001) Analysis of relative gene expression data using real-time quantitative PCR and the 2(-Delta Delta C(T)) Method. Methods 25:402-408.

Long XY, Wang JR, Ouellet T, Rocheleau H, Wei YM, Pu ZE, Jiang QT, Lan XJ and Zheng YL (2010) Genome-wide identification and evaluation of novel internal control genes for Q-PCR based transcript normalization in wheat. Plant Mol Biol 74:307-311.

Maruyama K, Sakuma Y, Kasuga M, Ito Y, Seki M, Goda H, Shimada Y, Yoshida S, Shinozaki K and Yamaguchi-Shinozaki K (2004) Identification of cold-inducible downstream genes of the Arabidopsis DREB1A/CBF3 transcriptional factor using two microarray systems. Plant J 38:982-993.

Medina J, Bargues M, Tero J, Pérez-Alonso M and Salinas J (1999) The Arabidopsis CBF gene family is composed of three genes encoding AP2 domain-containing proteins whose expression is regulated by low temperature but not by abscisic acid or dehydration. Plant Physiol 119:463-469.

Murray M and Thompson WF (1980) Rapid isolation of high molecular weight plant DNA. Nucleic Acids Res 8:4321-4325.
Nakano T, Suzuki K, Fujimura T and Shinshi H (2006) Genome-wide analysis of the ERF gene family. Plant Physiol 140:411-432.

Oakenfull RJ, Baxter R and Knight MR (2013) A C-repeat binding factor transcriptional activator (CBF/DREB1) from European Bilberry (Vaccinium myrtillus) induces freezing tolerance when expressed in Arabidopsis thaliana. PLoS One 8:e54119.

Pellegrineschi A, Reynolds M, Pacheco M, Brito RM, Almeraya R, Yamaguchi-Shinozaki K and Hoisington D (2004) Stress-induced expression in wheat of the Arabidopsis thaliana DREB1A gene delays water stress symptoms under greenhouse conditions. Genome 47:493-500.

Peng Y-L, Wang Y-S, Cheng H and Wang L-Y (2015) Characterization and expression analysis of a gene encoding CBF/DREB1transcription factor from mangrove Aegiceras corniculatum. Ecotoxicology 24:1733-1743.

Philipov S, Istatkova R, Yadamsurenghiin GO, Samdan J and Dangaa S (2007) A new 8,14-dihydropromorphinane alkaloid from Papaver nudicaule L. Nat Prod Res 21:852-856.

Qin F, Sakuma Y, Li J, Liu Q, Li Y-Q, Shinozaki K and Yamaguchi-Shinozaki K (2004) Cloning and functional analysis of a novel DREB1/CBF transcription factor involved in cold-responsive gene expression in Zea mays L. Plant Cell Physiol 45:1042-1052.

Sakuma Y, Liu Q, Dubouzet JG, Abe H, Shinozaki K and Yamaguchi-Shinozaki K (2002) DNA-binding specificity of the ERF/AP2 domain of Arabidopsis DREBs, transcription factors involved in dehydration- and cold-inducible gene expression. Biochem Biophys Res Commun 290:998-1009.

Seki M, Narusaka M, Abe H, Kasuga M, Yamaguchi-Shinozaki K, Carninci P, Hayashizaki Y and Shinozaki K (2001) Monitoring the expression pattern of 1300 Arabidopsis genes under drought and cold stresses by using a full-length cDNA microarray. Plant Cell 13:61-72.

Shan D-P, Huang J-G, Yang Y-T, Guo Y-H, Wu C-A, Yang G-D, Gao $Z$ and Zheng C-C (2007) Cotton GhDREB1 increases plant tolerance to low temperature and is negatively regulated by gibberellic acid. New Phytologist 176:70-81.

Shinwari ZK, Nakashima K, Miura S, Kasuga M, Seki M, Yamaguchi-Shinozaki K and Shinozaki K (1998) An Arabidopsis gene family encoding DRE/CRT binding proteins involved in low-temperature-responsive gene expression. Biochem Biophys Res Commun 250:161-170.

Stockinger EJ, Gilmour SJ and Thomashow MF (1997) Arabidopsis thaliana CBF1 encodes an AP2 domain-containing transcriptional activator that binds to the C-repeat/DRE, a cis-acting DNA regulatory element that stimulates transcription in response to low temperature and water deficit. Proc Natl Acad Sci USA 94:1035-1040.

Tamura K, Peterson D, Peterson N, Stecher G, Nei M and Kumar S (2011) MEGA5: Molecular Evolutionary Genetics Analysis using maximum likelihood, evolutionary distance, and maximum parsimony method. Mol Bio Evol 28:2731-2739.

Tatsis EC, Eylert E, Maddula RK, Ostrozhenkova E, Svato A, Eisenreich W and Schneider B (2014) Biosynthesis of Nudicaulins: $\mathrm{A}{ }^{13} \mathrm{CO}_{2}$-pulse/chase labeling study with Papaver nudicaule. Chem Biol Chem 15:1645-1650.

Timothy LB and Charles EL (1994) Fitting a mixture model by expectation maximization to discover motifs in biopolymers. In: Proceedings of the Second International 
Conference on Intelligent Systems for Molecular Biology, AAAI, Menlo Park, California, pp 28-36.

Tong Z, Hong B, Yang Y, Li Q, Ma N, Ma C and Gao J (2009) Overexpression of two Chrysanthemum DgDREB1 group genes causing delayed flowering or dwarfism in Arabidopsis. Plant Mol Biol 71:115-129.

Wang X, Chen X, Liu Y, Gao H, Wang Z and Sun G (2011) $C k D R E B$ gene in Caragana korshinskii is involved in the regulation of stress response to multiple abiotic stresses as an AP2/EREBP transcription factor. Mol Biol Rep $38: 2801-2811$.

Wang Z, Triezenberg SJ, Thomashow $\mathrm{M}$ and Stockinger EJ (2005) Multiple hydrophobic motifs in Arabidopsis CBF1 $\mathrm{COOH}-$ terminus provide functional redundancy in transactivation. Plant Mol Biol 58:543-559.

Xiao H, Siddiqua M, Braybrook S and Nassuth A (2006) Three grape $\mathrm{CBF} / \mathrm{DREB} 1$ genes respond to low temperature, drought and abscisic acid. Plant Cell Environ 29:1410-1421.

Yamaguchi-Shinozaki K and Shinozaki K (2006) Transcriptional regulatory networks in cellular responses and tolerance to dehydration and cold stresses. Annu Rev Plant Biol 57:781803.

Zhang M, Liu W, Bi Y-P and Wang Z-Z (2009) Isolation and identification of PNDREB1, a new DREB transcription factor from peanut (Arachis hypogaea L.) Acta Agron Sin 35:1973-1980.

\section{Supplementary material}

The following online material is available for this article:

Figure S1 - Nucleotide and deduced amino acid sequences of actin1 and EF1.

Figure S2 - Melting curves.

Figure S3 - Cloning of DREB1 from Iceland poppy.

Figure S4 - Motif logos in 36 DREB1s.

Table S1 - Primer sequences.

Associate Editor: Adriana S. Hemerly

License information: This is an open-access article distributed under the terms of the Creative Commons Attribution License (type CC-BY), which permits unrestricted use, distribution and reproduction in any medium, provided the original article is properly cited. 